\title{
Quality of root canal treatment performed by undergraduate students at the Wits Oral Health Centre
}

SADJ June 2021, Vol. 76 No. 5 p270 - p278

E Patel $^{1}$, AAM Ehbesh ${ }^{2}$, IE Munshi ${ }^{3}$, S Tootla ${ }^{4}$

\section{ABSTRACT}

\section{Purpose}

In 2012, the School of Oral Health Sciences at the University of the Witwatersrand modified its undergraduate endodontic curriculum which led to a need to assess the impact of curriculum changes on root canal treatment outcomes. This study was an audit of root canal treatment performed by undergraduate BDS students using postoperative radiographs, and compared the results between different undergraduate clinical years of study.

\section{Methodology}

Postoperative periapical radiographs of patients treated by undergraduate students were examined to assess length, density and taper. Two independent investigators were first calibrated, and thereafter assessed 299 endodontic cases that were performed by third, fourth and fifth year students during the 2013-2015 period at the Wits Oral Health Centre.

\section{Results}

$68.9 \%, 73.6 \%$ and $70.9 \%$ were found for adequate length, acceptable density and acceptable taper of root filling respectively. The most acceptable length, density and taper results were seen in patients treated by final year students, while the lowest results were observed in

\section{Author affiliations:}

1. Ebrahim Patel: BDS, MSc (Dent), Department of Paediatric and Restorative Dentistry, School of Oral Health Sciences, Faculty of Health Sciences, University of the Witwatersrand, Johannesburg, South Africa.

ORCID Number: 0000-0002-7683-4867

2. A Alaali M Ehbesh: BDS, MSc (Dent), Department of Conservative Dentistry and Endodontics, Faculty of Dentistry and Oral Surgery, Alasmarya University, Zliten, Libya.

3. Ismail E Munshi: BSc, BCHD, MDent, Department of Oral Rehabilitation, School of Oral Health Sciences, Faculty of Health Sciences, University of the Witwatersrand, Johannesburg, South Africa.

4. Saidah Tootla: BCHD, MScDent, Department of Paediatric \& Restorative Dentistry, School of Oral Health Sciences, Faculty of Health Sciences, University of the Witwatersrand, Johannesburg, South Africa.

Corresponding author: Ebrahim Patel

Department of Paediatric and Restorative Dentistry, School of

Oral Health Science, 7 York Road, Parktown, Johannesburg, 2193, South Africa.

Email: ebrahim.patel@wits.ac.za

Author contributions:

1. Ebrahim Patel: Principal author - $45 \%$

2. A Alaali M Ehbesh: Second author - $35 \%$

3. Ismail E Munshi: Third author - $15 \%$

4. Saidah Tootla: Fourth author $-5 \%$

\section{ACRONYMS}

AC: Apical Constriction

CDJ: CementoDentinal Junction

AF: Apical Foramen

AP: Apical Periodontitis

AAE: American Association of Endodontists

ESE: European Society of Endodontology

NiTi: Nickel-Titanium

PTN: ProTaper Next files

Mx: Maxillary

Mn: Mandibular

the fourth year student cohort. There was a tendency for third year students to overfill due to over-instrumentation of anterior teeth.

\section{Conclusion}

The change in the curriculum has been justified, though room for improvement exists. The superior result found in the 5th year student cohort was most likely due to their relative experience, and the use of rotary instrumentation and dental operating microscopes. Endodontic teaching should further emphasize the importance of length control during endodontic treatment and more stringent steps may be necessary during patient allocation and clinical supervision of fourth year dental students.

\section{Keywords}

Quality, root canal treatment, undergraduate student.

\section{INTRODUCTION}

Root canal treatment is a complicated procedure that requires careful attention to detail and meticulous execution. This allows for effective cleaning and shaping of the root canal while avoiding any procedural error that may impact treatment outcome. A prerequisite to achieving treatment at a high standard of care includes inventive training of dental students to elicit high quality treatment.

\section{Quality guidelines in root canal treatment}

The European Society of Endodontology (ESE) in 2013 expressed their concern that despite tremendous technical advances in endodontics, studies continue to exhibit displeasing technical results for endodontic treatment 
in European societies. ${ }^{1}$ The ESE 2013 guidelines quote several studies to prove that these results are a reflection of the achievement of the initial proficiency shown in undergraduate training where requirements remain variable. ${ }^{2-6}$ The society also emphasized the necessity of ensuring that undergraduate practice is performed to a standard that confirms thorough understanding of the crucial factors that play a role in clinical outcomes.

The ESE (2006) reported a set of guidelines for undergraduate syllabi, to promote the advancement of high quality undergraduate dental teaching. According to these guidelines, the student is expected to possess the ability to perform nonsurgical endodontic treatment on single and multi-rooted teeth. The guidelines also included the expectation that students should identify and know how to avoid any iatrogenic errors that might occur with conventional endodontic treatment. ${ }^{7,10}$ Educational guidelines dictate that dental schools ensure the competence of each graduating student in the field of endodontics. ${ }^{11}$

Eleftheriadis and Lambrianidis (2005) proposed that the assessment of technical outcomes of endodontic treatment and the detection of iatrogenic errors are based on the immediate postoperative radiographs. ${ }^{2}$ Consequently, the ESE (2006) advised that the quality of root canal filling should be assessed through postoperative radiographs. ${ }^{10}$

The use of periapical radiographs in root canal treatment

Periapical radiographs are commonly in endodontic treatment for preoperative diagnostic assessment, working length determination, master apical file fit, master cone and postoperative assessment of the quality of obturation.
Endodontic treatment success is often predicted by the quality of the root canal treatment, as depicted on postoperative radiographs. Although Siqueira (2001) agrees with this recommendation, he cautions that the radiographic judgement of the root filling may not be indicative of root canal sealing. ${ }^{12}$ The author concluded that the major cause of failure of most well-treated endodontic treatment cases is due to persistence of infection. It should be recognized that periapical radiographs represent a two dimension image and have limitations, such as the superposition with adjacent tooth structures, especially in the region of the maxillary molars. ${ }^{13,14}$

Numerous studies have used postoperative radiographs to assess the quality of root canal treatment. Table 1. describes studies that assessed the quality of endodontic treatment performed by undergraduate students by examining postoperative radiographs. Although there is considerable consistency among the studies listed, not all the studies used the same criteria.

\section{Criteria used to determine the quality of root canal treatment}

Various studies have shown that the outcome of root canal treatment is dependent on the technical quality of the root canal filling. ${ }^{24-26}$ In addition, studies have also used the absence of voids and the length of root fillings as assessment criteria. ${ }^{24,27,28}$ Furthermore, Santos et al. (2010) considered the length, density and taper of root canal fillings in their assessment of the quality of root canal treatment, while Bołtacz-Rzepkowska and Pawlicka (2003) concluded that the radiographic technical quality of root canal treatment is more related to the health of the periapical area, rather than substandard root fillings. ${ }^{29,30}$ Ramachandran Nair (2003) reinforced the view that the

\begin{tabular}{|c|c|c|c|c|c|}
\hline Authors & Year & Students & Criteria & Country & Sample \\
\hline $\begin{array}{l}\text { Greene and } \\
\text { Krell }^{15}\end{array}$ & 1990 & $3^{\text {rd }}$ year students. & Ledge formation. & USA & 171 cases or 336 canals. \\
\hline $\begin{array}{l}\text { Kapalas and } \\
\text { Lambrianidis }^{16}\end{array}$ & 2000 & $\begin{array}{l}\text { Undergraduate } \\
\text { clinic and } \\
\text { endodontists. }\end{array}$ & Ledge formation. & Greece & $\begin{array}{l}626 \text { root canals ( } 367 \text { by } \\
\text { undergraduate students). }\end{array}$ \\
\hline $\begin{array}{l}\text { Barrieshi-Nusair } \\
\text { et al. } .^{7}\end{array}$ & 2004 & $4^{\text {th }}$ and $5^{\text {th }}$ year. & Length, density and taper. & Jordan & 542 teeth or 912 root canals. \\
\hline $\begin{array}{l}\text { Eleftheriadis and } \\
\text { Lambrianidis }^{2}\end{array}$ & 2005 & $4^{\text {th }}$ and $5^{\text {th }}$ year. & $\begin{array}{l}\text { Length, density, ledge, perforations (root, furcation } \\
\text { and strip) fractured instruments. }\end{array}$ & Greece & 620 root canals 388 teeth. \\
\hline Er et al. ${ }^{18}$ & 2006 & $4^{\text {th }}$ and $5^{\text {th }}$ year. & Length, density and taper. & Turkey & $\begin{array}{l}1893 \text { teeth or } 3692 \text { root } \\
\text { canals. }\end{array}$ \\
\hline $\begin{array}{l}\text { Lynch and } \\
\text { Burke }^{11}\end{array}$ & 2006 & Undergraduate & Length and density. & Ireland & 100 single rooted teeth. \\
\hline Pettigrew et al. ${ }^{19}$ & 2007 & Undergraduate & $\begin{array}{l}\text { Length, and presence of voids, fractured instruments } \\
\text { and perforation. }\end{array}$ & Scotland & 100 single rooted teeth. \\
\hline Balto et $a^{20}$ & 2010 & $4^{\text {th }}$ and $5^{\text {th }}$ year & $\begin{array}{l}\text { Length, Density, Taper, ledge, gouging, zipping, api- } \\
\text { cal transportation, fractured instruments, perfo- } \\
\text { rations (apical, root, strip and furcation), lack of } \\
\text { straight-line access and missed canal. }\end{array}$ & Saudi Arabia & 550 teeth. \\
\hline Khabbaz et al. ${ }^{6}$ & 2010 & $4^{\text {th }}$ and $5^{\text {th }}$ year & $\begin{array}{l}\text { Length, density, ledge, fractured instruments, perfo- } \\
\text { rations (foramen and root). }\end{array}$ & Greece & 1109 root canals or 759 teeth. \\
\hline Rafeek et al. ${ }^{21}$ & 2012 & Undergraduate & $\begin{array}{l}\text { The length, presence of voids, taper, curvature of } \\
\text { canal and fractured instruments. }\end{array}$ & Trinidad & 288 or 460 root canals. \\
\hline $\begin{array}{l}\text { Román Richon } \\
\text { et al. }{ }^{22}\end{array}$ & 2014 & $4^{\text {th }}$ year students & Length, density and taper. & Spain & 561 extracted teeth. \\
\hline Smadi et al. ${ }^{23}$ & 2015 & $4^{\text {th }}$ and $5^{\text {th }}$ year & $\begin{array}{l}\text { Length, density, taper, ledge, transportation and per- } \\
\text { foration. }\end{array}$ & Jordan & 213 teeth. \\
\hline
\end{tabular}


primary cause of postoperative apical periodontitis (AP) in well-treated teeth is due to the presence of microbial infection. ${ }^{31}$

When examining postoperative radiographs, several criteria act as predictors of successful endodontic treatment outcome. Some of which include: (1) length of root canal filling, (2) density of the root canal filling, and (3) taper of the root canal.

\section{Length of the root canal filling}

The length of the root canal filling is an important evaluative parameter and is determined by measuring the apical terminus of the obturation from the radiographic apex of the tooth on postoperative radiographs. Zhong et al. (2008) showed that microbes and their by-products are responsible for the failure of endodontic treatment in teeth with inadequate length of condensed obturation material and a low density of the obturation. ${ }^{32}$

Underfilling results in voids in the apical region of the canal which subsequently provides spaces for bacterial colonization. On the other hand, overfilling of the obturation material is the extension of a semi-solid or solid core root canal material beyond the apical foramen. ${ }^{33}$ Schaeffer et al. (2005) stated that extruded obturation material beyond the radiographic apex correlated with a decreasing prognosis of root canal treatment while Siqueira (2001) associated overfilling with intraradicular and/or extraradicular concomitant infections. ${ }^{12,34}$ The ESE has suggested that the working length should be determined between 0.5 $-2 \mathrm{~mm}$ from the radiographic apex. ${ }^{10}$ This is the guideline that is prescribed at the University and was thus used in this study.

\section{Density of the root canal filling}

The density of the root filling is another essential factor that influences the outcome or prognosis of endodontic therapy. Kirkevang et al. (2000) found that the presence of voids in root canal fillings have a substantial impact on the incidence of AP. ${ }^{35}$ Furthermore, Hommez et al. (2002) found that the incidence of AP had a $47.1 \%$ occurrence in samples of non-homogeneous root canal filling, and a $27.7 \%$ occurrence in samples of homogeneous root canal filling. ${ }^{36}$ Periapical radiographs are used to determine the quality of root canal treatment by qualifying the homogeneity of obturation, which depends on the absence or presence of voids. ${ }^{6}$ In this study, the presence of voids in the root filling was considered unacceptable.

\section{Taper of the root canal filling}

The taper of the root canal is defined by Schilder (1974) as a continuous tapered funnel shape of the root canal system to enable cleaning and facilitate obturation. ${ }^{37}$ Root canal taper is a reflection of shaping the root canals and not the obturation. Arvaniti and Khabbaz (2011) reported that there was no substantial difference in root canal cleanliness between the different tapers $(0.04,0.06$ and 0.08$)$ in root canals that were prepared to an apical size 30.38 Zogheib et al. (2012) assessed the influence of different tapered preparation on the sealing ability of Real Seal 1 at the apical $5 \mathrm{~mm}$ of the obturated canals using micro-CT for analysis. ${ }^{39}$ The results showed that the smallest taper size (0.04) had significantly greater volume of voids, while the large taper sizes (0.06 and 0.08 ) revealed fewer voids. In this study any inconsistent taper of canal preparation from crown to apex was considered unacceptable. Table 2 portrays the results of various studies utilizing length, density and taper to determine the quality of the root canal treatment.

Following the implementation of the revised endodontic curriculum at the Wits School of Oral Health Sciences in 2012, no study has been done to assess the impact of the curriculum change on treatment outcomes. The aim of this study was to assess the quality of root canal treatment performed by undergraduate students at the Wits Oral Health Centre.

\section{MATERIALS AND METHODS}

This was a retrospective study, composed of 299 postoperative periapical radiographs of patients treated by $3^{\text {rd }}, 4^{\text {th }}$ and $5^{\text {th }}$ year undergraduate dental students, in the Wits Oral health Centre at the School of Oral Health Sciences (University of the Witwatersrand), between January 2013 and December 2015.

The endodontic patients' radiographs were examined using a magnifying lens (2x magnification) and an endodontic ruler in a dark room using a radiographic viewer. Twenty cases, not included in the study sample, were used to compare the interrater agreement between the

\begin{tabular}{|c|c|c|c|c|c|c|c|}
\hline \multirow{3}{*}{ Authors } & \multirow{3}{*}{ Year } & \multirow{3}{*}{ Country } & \multicolumn{5}{|c|}{ Results } \\
\hline & & & \multicolumn{3}{|c|}{ Length } & \multirow[t]{2}{*}{ Density } & \multirow{2}{*}{ Taper } \\
\hline & & & Adequate & Underfilling & Overfilling & & \\
\hline Barrieshi-Nusair et al. & 2004 & Jordan & $61.3 \%$ & $34.5 \%$ & $4.2 \%$ & $72.6 \%$ & $85.3 \%$ \\
\hline Eleftheriadis and Lambrianidis & 2005 & Greece & $62.7 \%$ & $7.4 \%$ & $1.8 \%$ & $82.6 \%$ & - \\
\hline Er et al. & 2006 & Turkey & $69.6 \%$ & $17.4 \%$ & $13 \%$ & $53.2 \%$ & $68.3 \%$ \\
\hline Lynch and Burke & 2006 & Ireland & $70 \%$ & $21 \%$ & $9 \%$ & $90 \%$ & - \\
\hline Pettigrew et al. & 2007 & Scotland & $80 \%$ & $5 \%$ & $15 \%$ & $80 \%$ & - \\
\hline Balto et al. & 2010 & K.S.A & $79.6 \%$ * & $11.3 \%$ & $9.1 \%$ & $34.9 \%$ & $59.6 \%$ \\
\hline Rafeek et al. & 2012 & Trinidad & $63.1 \%$ & $24.3 \%$ & $12.6 \%$ & $27.6 \%$ & $72.2 \%$ \\
\hline Smadi et al. & 2015 & Jordan & $61.5 \%$ & $14.1 \%$ & $24.4 \%$ & $50.5 \%$ & $56.1 \%$ \\
\hline
\end{tabular}


two main investigators. Ethical clearance and permission to conduct the study was obtained from the Human Research Ethics Committee (Wits University) and the Risk Assesment committee (Wits Oral Health Centre).

Criteria for study inclusion incorporated all teeth endodontically treated by the third, fourth and fifth year undergraduate students under supervision, teeth with complete root apices excluding $3^{\text {rd }}$ molars, completed root canal treatment, patient files with postoperative radiographic records of good condition, and postoperative radiographs exhibiting a minimum of $2 \mathrm{~mm}$ beyond the root apex. Any teeth with complex anatomy such as severe root canal curvature, root fracture, or root resorption (external or internal) prior to root canal obturation were excluded from the study.

The three main criteria assessed on the postoperative radiographs were: length, density and taper. Length of the root filling was characterised as 'Adequate' where the root filling was $0-2 \mathrm{~mm}$ from radiographic apex, "Overfilling" when the root filling extending beyond the radiographic apex, and "Underfilling" when the root filling was $>2 \mathrm{~mm}$ from the radiographic apex.

The Density of the root filling was regarded as "Acceptable" when there were no voids between root filling and root canal walls or within the root filling, and "Unaccept- able" when voids were present between root filling and root canal walls or within the root filling. The taper of the root canal was regarded as "Acceptable" when there was a consistent taper from the orifice to the root apex, and "Unacceptable" when the taper was inconsistent.

IBM SPSS 24.0 was used for analysis. Cohen's Kappa was used to measure the inter-rater reliability of the root canal treatment variables between two clinicians. Descriptive statistics of frequency and percentages were used for data summary. Inferential statistics using Fischer's exact test were used to determine the association between independent and dependent variables.

\section{RESULTS}

Inter-rater agreement was determined using Cohen's kappa across the three assessed parameters. The results was determined as 1.00 (length of root filling), 0.93 (density), and 0.77 (taper).

The distribution of the 299 included patient cases for the third, fourth and fifth year students were 85, 106 and 108 respectively. The distribution of tooth location and position are shown in Table 3.

The quality of the root canal filling was determined by reporting the length, density and taper of the root canal

\begin{tabular}{|c|c|c|c|c|c|c|c|c|c|c|}
\hline \multirow{2}{*}{\multicolumn{2}{|c|}{ Teeth characteristics }} & \multicolumn{2}{|c|}{ Third year } & \multicolumn{2}{|c|}{ Fourth year } & \multicolumn{2}{|c|}{ Fifth year } & \multicolumn{2}{|c|}{ Total } & \multirow{2}{*}{$p$ value } \\
\hline & & $\mathbf{N}$ & $\%$ & $\mathbf{N}$ & $\%$ & $\mathbf{N}$ & $\%$ & $\mathbf{N}$ & $\%$ & \\
\hline \multirow[t]{7}{*}{ Tooth type } & Central incisor & 47 & 55.3 & 27 & 25.5 & 26 & 24.1 & 100 & 33.1 & \multirow[t]{7}{*}{$<0.001$} \\
\hline & Lateral incisor & 29 & 34.1 & 9 & 8.5 & - & - & 37 & 12.7 & \\
\hline & Canine & 9 & 10.6 & 6 & 5.7 & 1 & 0.9 & 16 & 5.4 & \\
\hline & $1^{\text {st }}$ premolar & - & - & 17 & 16 & 8 & 7.4 & 25 & 8.4 & \\
\hline & $2^{\text {nd }}$ premolar & - & - & 28 & 26.4 & 8 & 7.4 & 36 & 12 & \\
\hline & $1^{\text {st }}$ molar & - & - & 14 & 13.2 & 38 & 35.2 & 53 & 17.7 & \\
\hline & $2^{\text {nd }}$ molar & - & - & 5 & 4.7 & 27 & 25.0 & 32 & 10.7 & \\
\hline \multirow[t]{2}{*}{ Teeth location } & Anterior & 85 & 100 & 41 & 38.7 & 27 & 25 & 153 & 51.2 & \multirow[t]{2}{*}{$<0.001$} \\
\hline & Posterior & - & - & 65 & 61.3 & 81 & 75 & 146 & 48.8 & \\
\hline \multirow[t]{2}{*}{ Teeth position } & Maxillary & 46 & 54.1 & 65 & 61.3 & 44 & 40.7 & 155 & 51.8 & \multirow[t]{2}{*}{$<0.001$} \\
\hline & Mandibular & 39 & 45.9 & 41 & 38.7 & 64 & 59.3 & 144 & 48.2 & \\
\hline
\end{tabular}

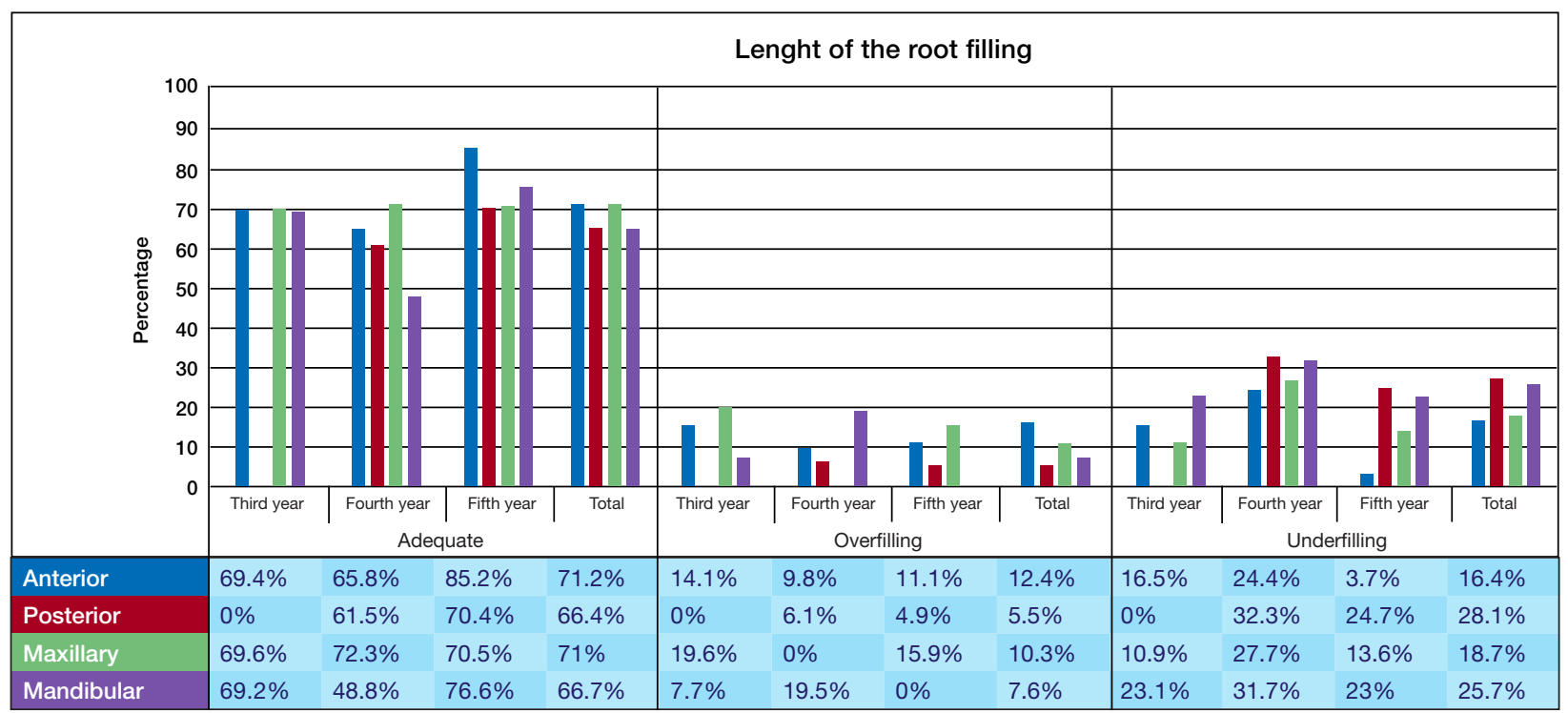

Figure 1. Length of the root filling categorized by tooth location and year of study. 
filling. The total number of canals with adequate length was $68.9 \%$, while total acceptable density of root filling was $73.6 \%$, and the total acceptable taper of root filling was $70.9 \%$.

The adequate length and overfilling results were higher in teeth with straight roots, than in teeth with moderately curved roots where a higher frequency of underfilling was noted. Figure 1 and Figure 2 summarizes the results of length, density and taper by tooth type and location across the three years of study.

The highest acceptable density and taper was recorded for central incisors, while the lowest was noted in sec-

\begin{tabular}{|c|c|c|c|c|}
\hline \multirow[t]{2}{*}{ Procedure } & \multicolumn{3}{|c|}{ Quota } & \multirow[t]{2}{*}{ Cumulative quota } \\
\hline & $\begin{array}{l}\text { Third } \\
\text { year }\end{array}$ & $\begin{array}{l}\text { Fourth } \\
\text { year }\end{array}$ & $\begin{array}{l}\text { Fifth } \\
\text { year }\end{array}$ & \\
\hline Single-rooted teeth & 2 & 2 & 1 & 5 \\
\hline Dual-rooted teeth & - & 2 & 2 & 4 \\
\hline Multi-rooted teeth & - & 2 & 2 & 4 \\
\hline Re-treatment & - & - & 1 & 1 \\
\hline $\begin{array}{l}\text { Use of microscope } \\
\text { - molar tooth* }\end{array}$ & - & - & 1 & 1 \\
\hline
\end{tabular}

ond molars. 'Acceptable' density and taper was greater in teeth with straight roots than in teeth that had moderately curved roots.

\section{Acceptable root canal filling}

An acceptable root canal filling is based on length and density or length, density and taper of the filling (Figure 3). Acceptable root filling based on the length and density were greater than $63 \%$ in all years. However, the treatment performed by the fifth year students $(71.9 \%)$ revealed the highest acceptable root filling when compared to the third year students $(69.4 \%)$ and the $4^{\text {th }}$ year students (63.2\%).

Acceptable root canal filling based on the length, density and taper were greater than 55\% in all student years. However, the teeth treated by the $4^{\text {th }}$ year students were the least acceptable result (55.7\%) when compared to the $5^{\text {th }}$ year $(68.5 \%)$ and $3^{\text {rd }}$ year $(63.5 \%)$ students, as shown in Figure 3.

The Fischer's exact test was used to examine the association between year of study and the quality of root canal filling. The test revealed that there was no significant association between the year of study and all the measures of quality of the root canal filling $(p>0.05)$.

\begin{tabular}{|c|c|c|c|c|c|c|c|}
\hline \multirow[t]{3}{*}{ Authors } & \multirow[t]{3}{*}{ Year } & \multirow[t]{3}{*}{ Country } & \multicolumn{5}{|c|}{ Results } \\
\hline & & & \multicolumn{3}{|c|}{ Length } & \multirow[t]{2}{*}{ Density } & \multirow[t]{2}{*}{ Taper } \\
\hline & & & Adequate & Underfilling & Overfilling & & \\
\hline Barrieshi-Nusair et al. & 2004 & Jordan & $61.3 \%$ & $34.5 \%$ & $4.2 \%$ & $72.6 \%$ & $85.3 \%$ \\
\hline Eleftheriadis and Lambrianidis & 2005 & Greece & $62.7 \%$ & $7.4 \%$ & $1.8 \%$ & $82.6 \%$ & - \\
\hline Er et al. & 2006 & Turkey & $69.6 \%$ & $17.4 \%$ & $13 \%$ & $53.2 \%$ & $68.3 \%$ \\
\hline Lynch and Burke & 2006 & Ireland & $70 \%$ & $21 \%$ & $9 \%$ & $90 \%$ & - \\
\hline Pettigrew et al. & 2007 & Scotland & $80 \%$ & $5 \%$ & $15 \%$ & $80 \%$ & - \\
\hline Balto et al. & 2010 & K.S.A & $79.6 \%$ * & $11.3 \%$ & $9.1 \%$ & $34.9 \%$ & $59.6 \%$ \\
\hline Rafeek et al. & 2012 & Trinidad & $63.1 \%$ & $24.3 \%$ & $12.6 \%$ & $27.6 \%$ & $72.2 \%$ \\
\hline Smadi et al. & 2015 & Jordan & $61.5 \%$ & $14.1 \%$ & $24.4 \%$ & $50.5 \%$ & $56.1 \%$ \\
\hline Current study & 2017 & R.S.A & $68.9 \%$ & $22.1 \%$ & $9 \%$ & $73.6 \%$ & $70.9 \%$ \\
\hline
\end{tabular}

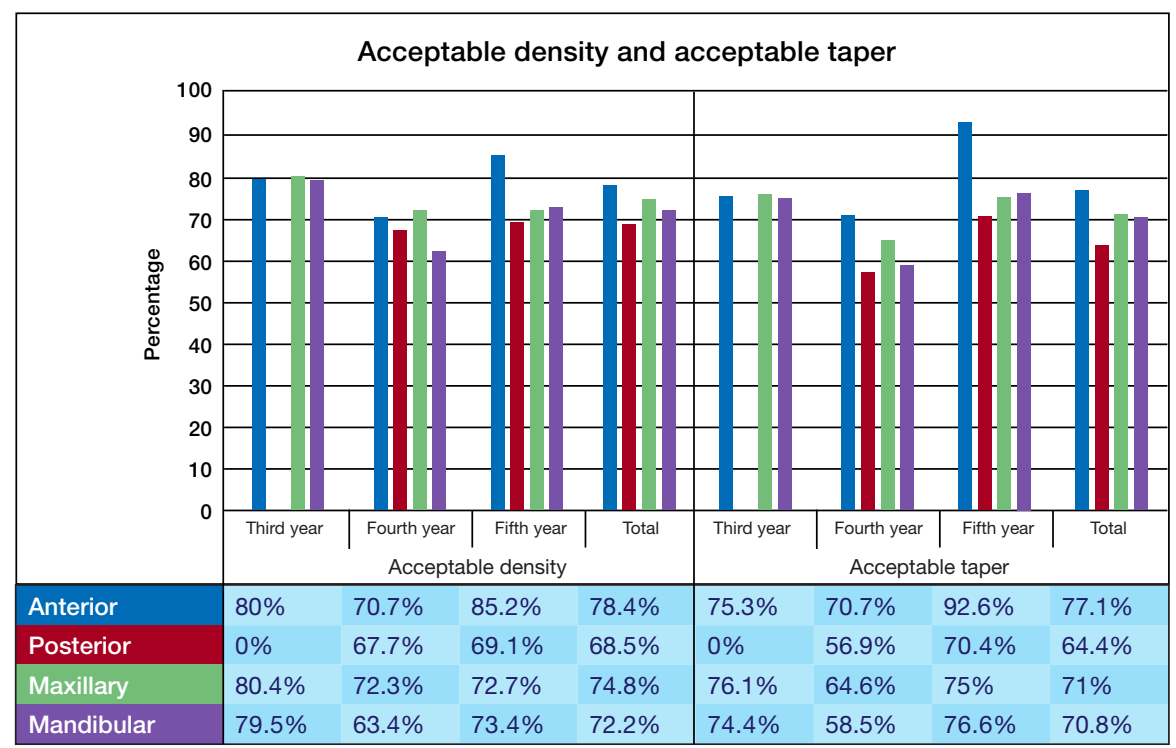

Figure 2. Acceptable density and acceptable taper categorized by tooth location and year of study. 


\section{DISCUSSION}

A new undergraduate curriculum was implemented in 2012 at the University of Witwatersrand, whereby the endodontic undergraduate preclinical course began in the second year, instead of the third year of study. Several changes were made to the didactic and clinical teaching schedule.

The absolute minimum clinical quota for undergraduate students at Wits Oral Health Centre is shown in Table 4. All clinical requirements (quota) for clinical students must be completed by the penultimate month of their final year of study.

The staff: student ratio is $1: 7$ for preclinical teaching and 1:5 for clinical teaching at the Wits Oral Health Centre.

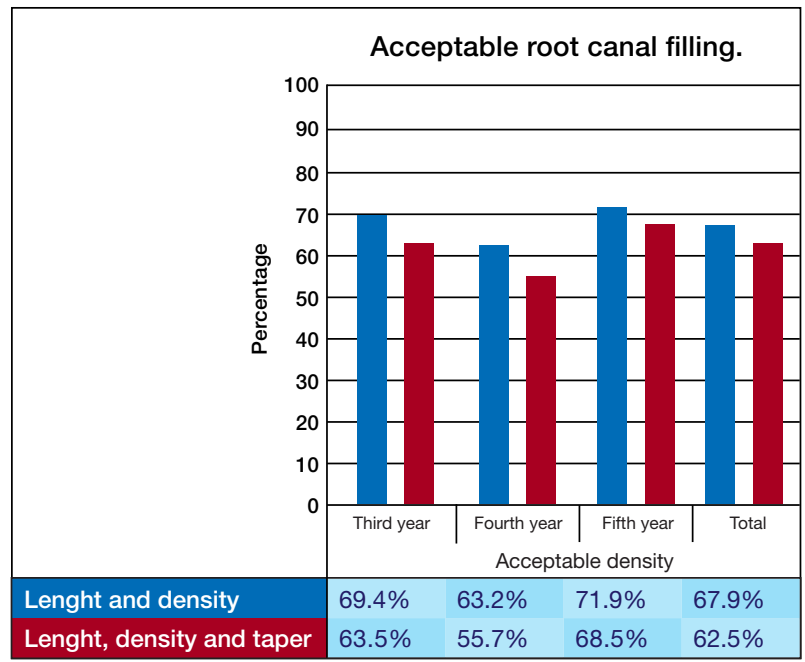

Figure 3. Acceptable root canal filling.
The preclinical staff:student's ratio was superior to those described by other authors with ratios of $(1: 8),{ }^{11}(1: 12)^{19}$ and $(1: 15){ }^{23}$ The time dedicated to preclinical endodontic teaching at Wits University is 60 hours, which is greater than the University Dental School and Hospital, Cork (48 hours), ${ }^{11}$ Glasgow Dental Hospital and School (32 hours) $)^{19}$ and the University of the West Indies (54 hours), ${ }^{21}$ while it was similar to the University of Jordan (56 hours). ${ }^{23}$

The clinical staff: student's ratio at Wits University of 1:5 was lower when compared to several other universities including Jordan University of Science and Technology (1:6), ${ }^{17}$ Aristotle University of Thessaloniki (1:8), ${ }^{2}$ University Dental School and Hospital, Cork (1:8), ${ }^{11}$ Glasgow Dental Hospital and School (1:12 for $5^{\text {th }}$ year), ${ }^{19}$ King Saud University (1:7 for $4^{\text {th }}$ year and $1: 2$ for $5^{\text {th }}$ year), ${ }^{20}$ the University of the West Indies $(1: 10)^{21}$ and finally the University of Jordan with a ratio of $1: 12 .{ }^{23}$ It is important to consider the influence of staff:student ratio when considering the outcomes of patient treatment under supervision. It is expected that a lower ratio allows for greater supervision decreasing the opportunity for mishaps while improving treatment quality and outcome.

Standard endodontic protocol in the $3^{\text {rd }}$ and $4^{\text {th }}$ years included the step-back preparation and lateral condensation obturation techniques. Stainless steel K-files with a triangular cross section were used with all files and cones being ISO 2\% tapered. A 2\% sodium hypochlorite irrigation solution was advocated for irrigation, coupled with the use of EDTA (RC Prep) for chelation and lubrication. The use of $2.5 x$ magnifying dental loupes was compulsory for all endodontic procedures. The root canal sealer available in the WOHC polyclinic was Topseal (Dentsply, South Africa).

\begin{tabular}{|c|c|c|c|c|c|c|c|c|c|}
\hline & & 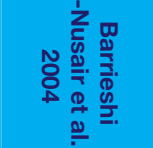 & 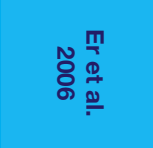 & 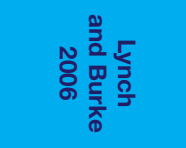 & 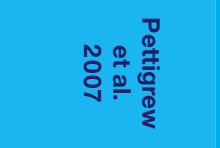 & 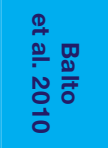 & 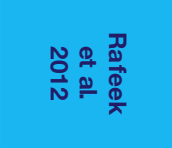 & 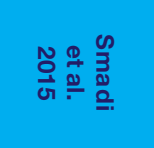 & 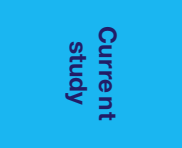 \\
\hline \multirow{3}{*}{$\begin{array}{l}\text { Adequate } \\
\text { length }\end{array}$} & Tooth & Mx Incisors & $\begin{array}{l}\text { Mn Premo- } \\
\text { lars }\end{array}$ & $\begin{array}{l}\text { Mn Lateral } \\
\text { incisors }\end{array}$ & $\begin{array}{l}\text { Mx } 2^{\text {nd }} \text { premolar } \\
\text { and Mn } 1^{\text {st }} \\
\text { premolar }\end{array}$ & Incisors & Mx Canines & Mx Anteriors & Central incisors \\
\hline & Arch & - & Maxillary & - & - & - & Maxillary & - & Maxillary \\
\hline & Location & - & - & - & - & - & Anterior & - & Anterior \\
\hline \multirow{3}{*}{ Overfilling } & Tooth & Mx Canines & Mn Incisors & $\begin{array}{l}\text { Mx Lateral } \\
\text { incisors }\end{array}$ & Mn Central Incisor & Molars & Mn Incisors & Mx Molars & Central incisors \\
\hline & Arch & - & Maxillary & - & - & - & Maxillary & - & Maxillary \\
\hline & Location & - & - & - & - & - & Anterior & - & Anterior \\
\hline \multirow{3}{*}{ Underfilling } & Tooth & Mn Molars & Mn Molars & $\begin{array}{l}\text { Mx } 2^{\text {nd }} \\
\text { Premolars }\end{array}$ & Mn Lateral incisor & Molars & Mx Molars & Mn Molars & $2^{\text {nd }}$ Molar \\
\hline & Arch & Mandibular & - & - & - & - & - & - & Mandibular \\
\hline & Location & - & - & - & - & - & - & - & Posterior \\
\hline \multirow[t]{3}{*}{ Density } & Tooth & Mx Canines & Mx Canines & $\begin{array}{l}\text { Mx Lateral, Mn } \\
\text { Central and } \\
\text { Lateral }\end{array}$ & $\begin{array}{l}\text { Mn Central, lateral } \\
\text { and Canines }\end{array}$ & Canines & Mn Incisors & Mx Anteriors & Central incisors \\
\hline & Arch & - & - & - & - & - & Maxillary & - & Maxillary \\
\hline & Location & - & - & - & - & - & No significant & - & Anterior \\
\hline \multirow{3}{*}{ Taper } & Tooth & Mn Canines & - & - & - & Canines & Mn Incisors & Mx Anteriors & Central incisors \\
\hline & Arch & & Mx Incisors & - & - & - & No significant & - & Maxillary \\
\hline & Location & - & - & - & - & - & Anterior & - & Anterior \\
\hline
\end{tabular}


The $5^{\text {th }}$ year students predominantly utilised rotary instrumentation for canal preparation which included ProGlider (Dentsply, South Africa) files for glide path preparation followed by Protaper Next (Dentsply, South Africa) files to complete canal preparation. The endodontic clinical protocol specified certain radiographs that should be taken during and after every root canal treatment.

Thus, no additional radiographs were required for this retrospective study. Teeth were excluded from the study when these radiographs were unreadable or unavailable. Standard endodontic protocol ensured that all endodontic radiographs be taken using an Endo Rinn $®$ instrument, at a preset exposure to ensure image quality.

The European Society of Endodontology (1992) recommended that students have to perform endodontic treatment on uncomplicated teeth (single and multirooted), and they have to be familiar with problems encountered in complicated endodontic treatments. ${ }^{7}$

The ESE, in their definition of uncomplicated treatment, included tooth curvature of less than $15^{\circ}$ from the axis of the roots. The $3^{\text {rd }}$ year students treated only the anterior teeth of which $75.3 \%$ were straight, while the $4^{\text {th }}$ year students treated posterior teeth $(61.3 \%)$ for the first time in the clinic, of which $58.5 \%$ were moderately curved teeth.

These differences in the complexity of cases between the different student groups explain why the result of the $3^{\text {rd }}$ year students in general was better than the $4^{\text {th }}$ year students. There was a significant difference in the number of roots and root curvature of the teeth treated between the $3^{\text {rd }}, 4^{\text {th }}$ and the $5^{\text {th }}$ year students $(p<0.001)$. One method to limit relatively difficult cases being allocated to novice undergraduate students is for supervisors to screen and allocate patients accordingly to ensure careful patient selection for students in the different clinical years of study.

The third year students had the lowest percentage of underfilled canals when compared to the $4^{\text {th }}$ and $5^{\text {th }}$ year students (16.5\%, 29.2\% and $19.4 \%$ respectively). Yet interestingly, the $3^{\text {rd }}$ year students had the highest number of overfilled canals $(14.1 \%, 7.5 \%$ and $6.5 \%$ respectively). This was attributed to this these students only treating anterior teeth with relatively wider and straight canals with little difficulty in finding the full length. However, a possible explanation for their high rate of overfilling is their inexperience and their inability to confine the instrumentation to within the canal. Thus, the high rate of overfilling was possibly due to over-instrumentation.

Thus, it is advised that greater emphasis be placed on working length control throughout canal preparation procedures during preclinical teaching. The density and taper of maxillary teeth treated by the $3^{\text {rd }}$ year students was better than in the mandibular teeth. The simple explanation for this is the relative difference in the size of the canals; that maxillary teeth have larger canals than mandibular teeth.

In this study, $35.5 \%$ of the teeth assessed were treated by the $4^{\text {th }}$ year students. $61.3 \%$ of these teeth were posterior teeth with $58.5 \%$ of them presenting moderately curved roots. With the exception of overfilling, the results of the main criteria assessed (length, density and taper) show that the fourth year students produced the lowest quality rating among all student years.

Anterior teeth treated by the $4^{\text {th }}$ year students displayed a higher prevalence of adequate length, underfilling, acceptable density and taper when compared to posterior teeth. These results were attributed to the inexperience of this student cohort in treating posterior teeth. In addition, the inexperience of the students were compounded by the allocation of relative challenging root canal anatomy cases.

$75 \%$ of treated teeth by the $5^{\text {th }}$ year students were posterior teeth, with $72.2 \%$ of these teeth presenting with moderately curved roots and $67.6 \%$ being multirooted teeth. The $5^{\text {th }}$ year students had the best adequate length and overfilling results which highlighted the impact of experience in the ultimate quality of root canal treatments, more so when treating teeth with more challenging anatomy. In addition, the use of rotary endodontic systems and more advanced methods of magnification account for the superior findings in this student group.

\section{Total acceptable root canal filling}

The total acceptable root canal filling of this study, based on the length and density, was $67.9 \%$. This result was higher than the studies by Eleftheriadis and Lambrianidis (2005) at 55.3\%, and Khabbaz et al. (2010) at 54.8\%. Similar to other studies, the $5^{\text {th }}$ year student cohort performed superior. ${ }^{6}$

The total acceptable root filling based on the length, density and taper was 62.5\%, which was better than the University of Pretoria study by Mostert \& Jonker (2016) $(59,66 \%)$, Barrieshi-Nusair et al. (2004) (47.4\%), Er et al. (2006) (33\%) and Smadi et al. (2015), which was $29.2 \% .^{17,18,23,40}$ Again, similar to Balto (2010), the $5^{\text {th }}$ year student cohort performed superior to earlier years of study. ${ }^{20}$ Table 5. and Table 6. summarize the results of previous studies across the 3 parameters assessed, and include the results of this study for comparison.

\section{CONCLUSIONS}

The results of this study indicated that the quality of root canal treatment performed by undergraduate students is similar to other studies conducted at various dental schools around the world. The change in the curriculum has been justified, though room for improvement exists. There was a tendency for third year students to overfill due to over-instrumentation of anterior teeth.

The $5^{\text {th }}$ year students had better results because of their relative experience and the opportunity to use dental operating microscopes. Endodontic teaching should further emphasise the importance of length control during endodontic treatment and more stringent steps may be necessary during patient allocation and clinical supervision of fourth year dental students. 


\section{References}

1. De Moor R, Hülsmann M, Kirkevang LL, Tanalp J, Whitworth J. Undergraduate Curriculum Guidelines for Endodontology. International Endodontic Journal. 2013 46(12): 1105-14.

2. Eleftheriadis G, Lambrianidis T. Technical Quality of Root Canal Treatment and Detection of latrogenic Errors in an Undergraduate Dental Clinic. International Endodontic Journal. 2005; 38(10): 725-34.

3. Sonntag D, Bärwald R, Hülsmann M, Stachniss V, Pre-Clinical Endodontics: a Survey Amongst German Dental Schools. International Endodontic Journal, 2008; 41(10): 863-8.

4. Burke F, Lynch C, Ní Ríordáin R, Hannigan A. Technical Quality of Root Canal Fillings Performed in a Dental School and the Associated Retention of Root-Filled Teeth: A Clinical Follow-up Study over a 5-Year Period. Journal of Oral Rehabilitation. 2009; 36(7): 508-15

5. Kelbauskas E, Andriukaitiene L, Nedzelskiene I. Quality of Root Canal Filling Performed by Undergraduate Students of Odontology at Kaunas University of Medicine in Lithuania. Stomatologija. 2009; 11(3), 92-6.

6. Khabbaz M, Protogerou E, Douka E. Radiographic Quality of Root Fillings Performed by Undergraduate Students. International Endodontic Journal. 2010; 43(6): 499-508.

7. European Society of Endodontology. Undergraduate Curriculum Guidelines for Endodontology. International Endo-dontic Journal. 1992; 25(3); 169-72.

8. Wesselink PR. Consensus Report of the European Society of Endodontology on Quality Guidelines for Endodontic Treatment. International Endodontic Journal. 1994; 27(3): 115-24.

9. Lost C. Undergraduate Curriculum Guidelines for Endodontology. International Endodontic Journal. 2001; 34(8): 574-80.

10. Loest C. Quality Guidelines for Endodontic Treatment: Consensus Report of the European Society of Endodontology. International Endodontic Journal. 2006; 39(12): 921-30.

11. Lynch C, Burke F. Quality of Root Canal Fillings Performed by Undergraduate Dental Students on Single-Rooted Teeth. European Journal of Dental Education. 2006; 10(2), 67-72.

12. Siqueira J. Aetiology of Root Canal Treatment Failure: Why Well-Treated Teeth Can Fail. International Endodontic Journal. 2001; 34(1): 1-10.

13. Tamse A, Kaffe I, Fishel D. Zygomatic Arch Interference with Correct Radiographic Diagnosis in Maxillary Molar Endodontics. Oral Surgery, Oral Medicine, Oral Pathology. 1980 50(6): 563-65.

14. Ridao-Sacie C, Segura-Egea JJ, Fernández-Palacín A, BullónFernández P, Ríos-Santos JV. Radiological Assessment of Periapical Status using the Periapical Index: Comparison of Periapical Radiography and Digital Panoramic Radiography. International Endodontic Journal, 2007; 40(6): 433-40.

15. Greene KJ, Krell KV. Clinical Factors Associated with Ledged Canals in Maxillary and Mandibular Molars. Oral Surgery, Oral Medicine, Oral Pathology. 1990; 70(4): 490-7.

16. Kapalas A, Lambrianidis T. Factors Associated with Root Canal Ledging during Instrumentation. Dental Traumatology. 2000; 16(5): 229-31.

17. Barrieshi-Nusair K, Al-Omari M, Al-Hiyasat A. Radiographic Technical Quality of Root Canal Treatment Performed by Dental Students at the Dental Teaching Centre in Jordan. Journal of Dentistry. 2004; 32(4): 301-07.

18. Er O, Sagsen B, Maden M, Cinar S, Kahraman Y. Radiographic Technical Quality of Root Fillings Performed by Dental Students in Turkey. International Endodontic Journal. 2006; 39(11): 867-72.

19. Pettigrew LK, Jauhar S, Lynch CD, Savarrio L, Carrotte $P$, Hannigan A. An Audit of the Quality of Root Canal Treatments Performed by Undergraduate Dental Students on Single-Rooted Teeth in Glasgow Dental Hospital and School. The European Journal of Prosthodontics and Restorative Dentistry, 2007; 15(2): 72-6.
20. Balto H, Al Khalifah SH, Al Mugairin S, Al Deeb M, Al-Madi, E. Technical Quality of Root Fillings Performed by Undergraduate Students in Saudi Arabia. International Endodontic Journal, 2010: 43(4), 292-300.

21. Rafeek RN, Smith WA, Mankee MS, Coldero LG. Radiographic Evaluation of the Technical Quality of Root Canal Fillings Performed by Dental Students. Australian Endodontic Journal. 2012; 38(2): 64-9.

22. Román Richon S, Faus Matoses V, Alegre Domingo T, Faus Llácer V. Radiographic Technical Quality of Root Canal Treatment Performed Ex Vivo by Dental Students at Valencia University Medical and Dental School, Spain. Medicina Oral, Patología Oral Y Cirugía Bucal. 2014; 93-7.

23. Smadi L, Hammad M, El-Ma'aita A. Evaluation of the Quality of Root Canal Treatments Performed by Dental Undergraduates: Is There a Need to Review Preclinical Endodontic Courses? American Journal of Educational Research, 2015; 3(12): 1554-8.

24. Sjögren U, Hägglund B, Sundqvist G, Wing K. Factors Affecting the Long- Term Results of Endodontic Treatment. Journal of Endodontics. 1990; 16(10): 498-504.

25. Smith C, Setchell D, Harty F. Factors Influencing the Success of Conventional Root Canal Therapy - a Five-Year Retrospective Study. International Endodontic Journal. 1993; 6(6): 321-33.

26. Peak J, Hayes S, Bryant S, Dummer P. Endodontics: The Outcome of Root Canal Treatment. A Retrospective Study within the Armed Forces (Royal Air Force). British Dental Journal. 2001; 190(3): 140-4.

27. Nieuwenhuysen J, Aouar M, D'hoore W. Retreatment or Radiographic Monitoring in Endodontics. International Endodontic Journal. 1994; 27(2): 75-81.

28. Farzaneh M, Abitbol S, Friedman S. Treatment Outcome in Endodontics: the Toronto Study. Phases I and II: Orthograde Retreatment. Journal of Endodontics. 2004; 30(9): 627-33.

29. Santos SMC, Soares JA, Costa GM, Brito-Júnior M, Moreira AN, de Magalhães CS. Radiographic Parameters of Quality of Root Canal Fillings and Periapical Status: A Retrospective Cohort Study. Journal of Endodontics. 2010; 36(12): 1932-7.

30. Bołtacz-Rzepkowska E, Pawlicka H. Radiographic Features and Outcome of Root Canal Treatment Carried out in the Łódz Region of Poland. International Endodontic Journal. 2003; 36(1): 27-32

31. Ramachandran Nair P. Non-microbial Etiology: Foreign Body Reaction Maintaining Post-treatment Apical Periodontitis. Endodontic Topics, 2003; 6(1): 114-34.

32. Zhong Y, Chasen J, Yamanaka R, Garcia R, Kaye EK, Kaufman JS, Cai J, Wilcosky T, Trope M, Caplan DJ. 2008. Extension and Density of Root Fillings and Postoperative Apical Radiolucencies in the Veterans Affairs Dental Longitudinal Study. Journal of Endodontics, 34(7), pp.798-803.

33. American Association of Endodontists. Glossary of Endodontic Terms. 2016. Available at: http://www.nxtbook.com/nxtbooks/ aae/endodonticglossary2016/ [Accessed 28 August 2017].

34. Schaeffer MA, White RR, Walton RE. Determining the Optimal Obturation Length: A Meta-Analysis of Literature. Journal of Endodontics. 2005; 31(4): 271-4.

35. Kirkevang LL, Ørstavik D, Hörsted-Bindslev P, Wenzel A. Periapical Status and Quality of Root Fillings and Coronal Restorations in a Danish Population. International Endodontic Journal. 2000; 33(6), 509-15

36. Hommez G, Coppens C, De Moor R. Periapical Health Related to the Quality of Coronal Restorations and Root Fillings. International Endodontic Journal. 2002; 35(8): 680-9.

37. Schilder $\mathrm{H}$. Cleaning and Shaping the Root Canal. The Dental Clinics of North America. 1974; 18: 269-96.

38. Arvaniti IS, Khabbaz MG. Influence of Root Canal Taper on its Cleanliness: a Scanning Electron Microscopic Study. Journal of Endodontics. 2011; 37(6): 871-4. 
39. Zogheib C, Naaman A, Medioni E, Arbab-Chirani R. Influence of Apical Taper on the Quality of Thermoplasticized Root Fillings Assessed by Micro-Computed Tomography. Clinical Oral Investigations. 2012; 16(5), 1493-8.

40. Mostert VC, Jonker $\mathrm{CH}$. An audit of root canal treatments completed by students and dentists at an academic hospital. South African Dental Journal. 2016; 71(4): s170-5.

\section{Do the CPD questionnaire on page 294}

The Continuous Professional Development (CPD) section provides for twenty general questions and five ethics questions. The section provides members with a valuable source of CPD points whilst also achieving the objective of CPD, to assure continuing education. The importance of continuing professional development should not be underestimated, it is a career-long obligation for practicing professionals.

\section{Online CPD in 6 Easy Steps}

1 Go to the SADA website www.sada.co.za.

2 Log into the 'member only' section with your unique SADA username and password.

3 Select the CPD navigation tab.

4 Select the questionnaire that you wish to complete.

5 Enter your multiple choice answers. Please note that you have two attempts to obtain at least $70 \%$.

6 View and print your CPD certificate. 